\title{
LA NO-DIRECTIVIDAD O LA PROGRAMACIÓN COMO MODELOS DE PLANIFICACIÓN Y EVALUACIÓN: FALSOS OPUESTOS EN BUSCA DE DIÁLOGO ${ }^{1}$
}

\author{
María Celina Chavarría González \\ Recibido 1-VIII-2002 • Aceptado 8-X-2002 \\ "Lo que los estudiantes aprenden del contenido for- \\ malmente sancionado es mucho menos importante que \\ lo que aprenden de los supuestos ideológicos encar- \\ nados en los tres sistemas comunicativos de la es- \\ cuela: el sistema curricular, el sistema de estilos peda- \\ gógicos de controlar la clase, y el sistema evaluativo."
}

Resumen: Desde la pedagogía crítica, dialéctica o transaccional y el paradigma de aprendizaje contextuado y sociohistórico de raíces Vygotskianas, se enfatiza que una visión que hace hincapié en el aprendizaje como transformación conjunta de las formas de participación nos instaría a poner nuestra mira más bien en los problemas de enseñanza, en nuestros diseños curriculares, en nuestra responsabilidad conjunta en la co-creación del desempoderamiento y apatía de los educandos ante las tareas de aprendizaje escolar. Se examina el mundo que ponemos a disposición de nuestros niños y niñas, al tratarlos como seres fragmentados, alienados y con un concepto de sí mismo a la vez vacío y consumidor, conceptos que desde la psicología social iluminarían la incidencia de nuestra programación curricular tanto en el etiquetamiento de dificultades de aprendizaje como de la cocreación de síndromes como el déficit atencional.

Palabras clave: Paradigma transacciónal, Enseñanza no directiva, Pedagogía crítica, Evaluación.

(Henry Giroux, 1990:72)

El currículo se encuentra tanto en el entorno como en nuestra filosofía-en-acción (De Alba, 1993). De hecho, siempre actuamos de acuerdo con nuestra interpretación de la realidad. ¿Cómo y para qué hacerla consciente?

La creación de un sí mismo vacío, basado en el tener, no en el ser, ha sido tema de exploración histórica (Cushman, 1990; Fromm, 1965). En la coyuntura actual, la subjetividad se forja de experiencias de un sí mismo fragmentado, alienado, vacío, inseguro de sus necesidades, a merced de lineamientos económicos que auspician la indulgencia de los deseos, el individualismo y el consumismo (Cushman, 1990).

¿Para qué examinar el mundo que ponemos al alcance de nuestra niñez, a través de la miríada de actividades, exhortaciones, ritmos, palabras y gestos? Podríamos con facilidad pensar que está bien en teoría (el papel aguanta todo), pero ¿qué tiene que ver con nuestro conducir diario en aulas repletas de estudiantes desmotivados 
y desmotivadas, ante una programación curricular por cumplir? Sin embargo, cada uno de nuestros actos es una afirmación cultural y conlleva un concepto del ser y sus posibilidades sociales.

"Los humanos, dado que son conciencia de sí y así conciencia del mundo, porque son un cuerpo consciente, viven una realidad dialéctica entre los condicionamientos y su libertad... Al tener el punto de decisión de su actividad en sí y sus relaciones con el mundo y con los otros, los humanos sobrepasan las 'situaciones límites' que no deben ser tomadas como si fueran barreras insuperables" (Freire, 1986:116, destacado nuestro).

Una de esas situaciones límite, en la coyuntura actual, implica cambiar de forma radical nuestros modelos de educación y diagnóstico. Argumentaremos, con base en una epistemología transaccional, que nuestros esfuerzos diagnósticos habrían de focalizar los problemas curriculares -problemas de enseñanza- más que los problemas de aprendizaje. ¡Hacer un viraje de la moral del consumo, del individualismo, del acaparamiento, a la ética del cuidado y responsabilidad social! ¿Cómo introducir cambios necesarios hacia un presente más acorde con valores de paz y desarrollo sostenible?

\section{Aportes de cosmovisiones transaccionales}

La cosmovisión transaccional, versión reciente que comprende la perspectiva dialéctica, el enfoque existencial-fenomenológico y la teoría socio-histórica profundizada por Vygotsky, apoya la noción de actores y ambientes como inseparables. La cosmovisión transaccional es holística y propone que lo analizable es la concurrencia de factores inseparables que dependen unos de otros, inclusive para su propia definición y significado. Sólo como un todo podemos analizar las relaciones cambiantes entre actores y contextos. Se trasciende la visión de los procesos psicológicos, por un lado, y los eventos del contexto social, por otro, más allá del concepto de influencias recíprocas $^{2}$ (Altman y Rogoff, 1987; Werner y Altman, 1998).

Las personas, los procesos y los contextos no pueden ser definidos o explicados por separado, como si fuesen átomos de la física newtoniana, sino solamente tal como funcionan mutuamente, como aspectos de una situación, como eventos. El ambiente se insinúa en todas las facetas de las personas (Altman y Rogoff, 1987/1991), por lo que no podemos describirlas o evaluarlas sin describir simultáneamente el contexto en el cual se manifiestan las características.

Comprenderás lo trascendente de esta perspectiva, la cual nos impide definir a nuestros chicos y chicas en términos generales, y nos instan más bien a comprender el flujo y la dinámica de los eventos, las acciones entrelazadas entre las personas y entre éstas y el ambiente, lo cual representa una práctica contestataria cifrada en la auto-observación y la reflexión con el fin de evitar esta práctica común. ${ }^{3}$

\section{El modelo mecanicista en crisis: la educación como parte del problema}

Como construcción social, el currículo es un proceso conceptual, ontológico y valorativo muy amplio y debe ser examinado e interpretado como tal (De Alba, 1993). Varios analistas coinciden en que los diseños curriculares prevalecientes están marcados por una ontología y epistemología de naturaleza conductista (Lündgren, 1985; Kliebard, 1985; Rogers, 1985; Wolfson, 1985). Desde distintas perspectivas, estos autores señalan que el modelo mecanicista, conductista, está en crisis. Inclusive los currículos de base constructivista, piagetianos, son frecuentemente plasmados en sus aspectos 
más mecánicos, según comentan, desde esta perspectiva, las innovadoras Constance Kamii y Rhetta Devries (1972).

Históricamente, ¿cómo se han ido plasmando estos problemas curriculares, donde toman vigencia los formatos más sencillos pero no los más relevantes, como todavía podemos apreciar en el enfoque hacia las adecuaciones curriculares? Anteriormente, los artesanos y artesanas aprendían con personas conocedoras de los oficios. Los carpinteros, por ejemplo, aprendían sobre la escogencia de maderas, el tinte, el cepillado, el barniz, los precios, los clientes, todo lo concerniente al proceso de producción y distribución. A partir de la Revolución Industrial, la educación se fue separando de las funciones de producción: se fue convirtiendo en un proceso donde el aprendizaje carecía de relación directa con el contexto productivo, circunstancia que el eminente sociólogo de la educación Pierre Bourdieu ha analizado en términos de su función de selección (Bourdieu y Passeron, 1977; cf. también Carnoy, 1976).

El sistema educativo, insisten, investigan y analizan estos autores, cumple la importante función de seleccionar por clases socioeconómicas. Su lenguaje y métodos abstractos favorecen a las clases medias y altas. Mayoritariamente aquellos que con apoyo familiar, económico e ideológico logran sobrevivir las múltiples pruebas de paciencia y las destrezas de clase media que les permiten culminar un recorrido académico bastante irrelevante y económicamente improductivo para la cotidianidad. Por otro lado, inculca hábitos de puntualidad, obediencia, sumisión, conducentes a una mayor adaptación e identificación con las condiciones sociales reinantes.

Nuestra sociedad canaliza una amplia gama de aprendizajes por intermedio de la escuela. No obstante, el sistema escolar, tal cual hoy se encuentra estructurado, en lugar de convertirse en un recurso para crear condiciones de empoderamiento que mitiguen las brechas sociales, está diseñado para ampliarlas, incrementando y ratificando las desigualdades (Apple, 1988; Bourdieu, 1987; 1987/1988; 1989; Bourdieu y Passeron, 1970/1977; Ferreiro y Teverovsky, 1979, 1990; Nimnicht, 1977; Perrenaud, 1974).

Este estilo de organización curricular abre las puertas a escogencias relativamente arbitrarias de temáticas curriculares, de modo que la reflexión directa sobre el sentido práctico y valorativo de la experiencia se dificulta y confunde por un sinnúmero de actividades fragmentarias que llenan los espacios de la vida. Contribuyen así a una vivencia del ser saturado, con disminuidas capacidades de ejercer su sentido crítico mientras hace frente a la miríada de detalles poco relevantes que sabe necesarios para 'ser alguien' en el mundo de vida globalizado (cf. Gergen, 1970). La escolarización, por lo tanto, se convierte en el problema de la educación, no en una solución.

El diseño curricular toma entonces creciente importancia para organizar un aprendizaje más abstracto y ha propiciado una pedagogía cada vez más fuera de contexto, más desvinculada de la vida real, de los requerimientos concretos del trabajo, del mundo actual, y de las formas en que se aprende, como se argumenta desde la perspectiva transaccional.

Nuestro pensamiento curricular está construido por nuestra visión del mundo, que nos empapa de una perspectiva de lo que aparenta ser "lo normal", "lo natural" en el entramado de coyunturas históricas y contextos económicos particulares. Nuestras vivencias, socialmente condicionadas, nos llevan a asumirlo acríticamente, a etiquetar a los educandos y tomar decisiones que les afectan. También a someternos, como educadores y educadoras, a una serie de constreñimientos y normativas asumidos como "naturales", como es el imperativo de aplicar currículos predeterminados. 
Los programas costarricenses todavía asumen la necesidad de abarcar ciertos "contenidos" ofrecidos gradualmente al educando en pequeñas porciones, de lo simple a lo complejo, de lo cercano a lo lejano, a pesar de las bien documentadas críticas de pensadoras como Maricela Rojas (1998: 42).

Así, por ejemplo, todavía intentamos enseñar sustantivos, verbos, adjetivos y artículos desde los primeros grados de la enseñanza básica hasta la secundaria, durante tantos años que nos lo hacen suponer como el sabor natural de la enseñanza escolar. En pequeñas dosis obligatorias, pues desde una visión atomista y conductual, supondríamos imposible expresarnos correctamente sin estas categorizaciones así dosificadas desde las épocas en que Omar Dengo todavía recorría las aulas costarricenses. Se hace caso omiso de la cantidad y calidad de investigaciones que indican que la mayoría de los pequeños y las pequeñas son tan geniales que reconstruyen las reglas de la gramática, sin ayuda de ejercicios ni tareas, antes de los cuatro años, mientras tengan personas a su alrededor que utilicen el lenguaje e interactúen cotidianamente en las formas aceptadas por las normas de la lengua. Pensar en uno o dos cursos de metalenguaje en secundaria, fundamentados en los retos del meta-análisis, en lugar de la serie de cursos de gramática, ¿sería demasiado radical y desestructurante? Y así sucesivamente, Juan Santamaría en pequeñas inyecciones desde la educación inicial hasta la secundaria, año tras año. Multiplicación y división de fracciones en la educación básica, sin saber bien por qué o para qué...

Ante las improntas del momento actual, con miras a propiciar generaciones más conscientes de su lugar en el planeta y de sus relaciones mutuas, resulta perentorio examinar estos paradigmas, pues nuestras acciones llevan significados implícitos, seamos conscientes de ello o no.

La serie de actos que de alguna manera se repiten en la cotidianidad escolar nos permite hablar de estructuras curriculares. La forma en que abordamos el currículo refleja nuestro estilo de contactar el mundo, las estrategias repetitivas y habituales de permitir y propiciar encuentros yo-mundo en la cotidianidad de un centro educativo.

En la historia de los debates curriculares, es usual discutir si se debe hacer énfasis en el niño y la niña como adquisidores $y$ descubridores del conocimiento (versiones constructivistas o piagetianas de niño-activo) o, por contraste, en las realidades programadas, donde los adultos y adultas son transmisores del conocimiento. Sin embargo, más recientemente, Rogoff señala que ambas polaridades obedecen a una misma metáfora y cosmovisión: la del conocimiento como un bien adquirido que se 'almacena' en el educando para su uso futuro, donde varía solamente la forma de 'conseguirlo' (1993; 1996, 1997).

Esta concepción rompe tradiciones en forma semejante al cambio de paradigma que implica pasar de la física newtoniana (cosmovisión mecanicista), a la cuántica, donde las decisiones sobre la definición de los fenómenos observados ejercen influencia simultánea no sólo sobre éstos sino también sobre otros fenómenos vinculados, aún cuando se encuentren a distancias geográficas impresionantes (cf. Capra, 1982).

Esta visión dinámica y de conexiones estrechas e intrínsecas conlleva implicaciones radicalmente distintas en términos de nuestras metas y métodos, por lo que se retoma una discusión de algunas implicaciones que encierra la clarificación de nuestros paradigmas.

\section{El modelo programado: la transmisión del conocimiento}

El modelo programado describe la iniciativa de los educadores y educadoras, quienes deciden las metas, los contenidos 
curriculares y los métodos, planifican las lecciones, organizan las actividades, guían la acción y dirigen los esfuerzos de los educandos. Este modelo de transmisión del conocimiento supone, predominantemente, que los alumnos y alumnas presten atención, lleven a cabo las actividades preparadas, contesten las preguntas, trabajen dentro de un marco definido de comportamiento aceptable y progresen hacia metas definidas por el programa, aún cuando fracciones del día puedan dedicarse al "trabajo en grupo" en torno a metas predefinidas (cf. Weikart, 1971).

Se trata de equipar a los pequeños y pequeñas con las habilidades y represiones ("el auto-control") necesarios para la educación tradicional, con énfasis en el pensamiento convergente y en la enseñanza de destrezas, contenidos, hábitos y referentes verbales; en la socialización y la adaptación. 'No poner atención a lo que el docente o la docente indica' es concebido como indisciplina, desadaptación, déficit atencional -aún cuando lo que estén tratando de 'enseñar' sea quizás íntimamente considerado como bastante irrelevante y aburrido.

Privilegiar la disciplina y la transmisión de conocimientos restringe la capacidad reflexiva, la iniciativa y la autoestima de los docentes y las docentes, no sólo de los jóvenes y las jóvenes, de manera que se coarta nuestro papel como transformadores y transformadoras intelectuales (Apple, 1988; Giroux, 1990). En nuestras sociedades, el carácter conservador de la educación ejerce una prevalencia de este modelo (cf. el clásico análisis de Bourdieu y Passeron al respecto).

\section{El modelo "centrado en el niño": la adquisición y el descubrimiento de la información}

Este modelo se caracteriza por un ambiente libre y abierto y una relación permisiva entre profesores y estudiantes.
Se concibe a los niños y niñas como iniciadores de las actividades, a los educadores y educadoras como facilitadores. La meta es ser "no directivos" y dejar que el interés de los educandos determine el contenido. Por ser controversial, a continuación abordaremos estos conceptos como parte de la discusión del 'marco abierto'.

\section{El modelo marco-abierto y más allá: la construcción conjunta del conocimiento y el aprendizaje como participación cultural plena}

El modelo marco abierto supone la siguiente convicción: las perspectivas del niño y la niña, mediante las cuales aprehenden la realidad, son fundamentalmente diferentes de las adultas, y su actividad es imprescindible para el aprendizaje. Empero, eso no basta. A diferencia del planteamiento 'centrado-en-el-niño', el papel de los adultos y adultas representa una irreemplazable y vital contribución al aprendizaje, al funcionar necesariamente como mediadores y transformadores de la cultura, desde sus conocimientos y valores.

La teoría piagetiana es usualmente citada para ejemplificar el modelo de marco abierto. La vertiente piagetiana, sin embargo, suele ser puesta en práctica de manera estática y adquisitiva, dirigida al logro de nociones clave. Aborda más bien el conocimiento como algo ' $a$ descubrir' por un niño o niña en solitario, al experimentar con el mundo físico (cf. Wertsch, 1988). Una vez que el educando logra equilibrar las disociaciones, este conocimiento descubierto es guardado dentro de sí para su utilización u operación posterior, lo cual es paradigmático de una metáfora que supone un conocimiento que se adquiere o descubre.

$\mathrm{Al}$ privilegiar la adquisición por descubrimiento, se omite la noción de participación plena de los adultos y adultas, quienes, en virtud del modelo, ceden aspectos esenciales de su palabra y su 
acción, en principio para promover la actividad constructivista por parte de los educandos. Con frecuencia, disfrazan sus intervenciones para propiciar, mediante preguntas cuyas respuestas son ya conocidas, el 'descubrimiento' novedoso de leyes físicas que en realidad son parte del patrimonio cultural (cf. Rojas, 1998). Para el estudiantado, esta forma de interrogación resulta transparente. A la vez, en forma etnocéntrica, este modelo asume metas de un desarrollo cognoscitivo abstracto, acordes a su visión desde el mundo industrializado. El modelo es, pues, mejor concebido como una amalgama entre el modelo 'centradoen-el-niño’ y el modelo programado.

Piaget mismo esboza su concepción de niveles de desarrollo alcanzados, como fases evolutivas del ser: proyecta los referentes culturales como entornos limitantes o propiciadores del 'desarrollo,' según las líneas evolutivas universales que su visión europea define. Es el adulto 'universal' europeo quien delimita los estadios y las metas del desarrollo tanto cognoscitivo como moral. Omite examinar dinámicamente la definición implícita sobre las metas e ideales trazados por él.

La visión sociocultural del desarrollo nos lleva más allá de un marco abierto. "Se abandona la idea de un mundo externo al individuo y de que el desarrollo consiste en adquirir conocimientos y habilidades independientes de la actividad [que se realiza] (Rogoff, 1997: 271)". El aprendizaje se visualiza como la transformación de la participación de las personas involucradas en actividades culturales. La noción de alcanzar estadios del pensamiento, generalizables a distintas áreas del conocimiento, es vista como falaz.

Concebir el desarrollo y el aprendiza$\mathrm{je}^{4}$ como procesos de transformación de la participación en la serie de actividades valoradas como deseables por subculturas en cuestión genera alcances radicalmente diferentes. Asumir el 'conocimiento' como una construcción conjunta en una comunidad nos lleva a poner la mira en las concepciones preconcebidas de lo significativo para los aprendices, los educadores y las metas de la colectividad (Rogoff, 1996, 1997; cf. también Lave y Wenger, 1971).

El conocimiento así concebido no se posee sino que representa una forma de actividad sociocultural, que no se encuentra ni en el educando, ni en la cultura. Los conocimientos no se pueden evaluar 'objetivamente', por lo que tampoco se puede diagnosticar a los niños o niñas fuera del contexto concreto. Cualquier forma de evaluación es otra forma de $a c$ tividad cultural, con sus significados sociohistóricos. Es imposible, por definición, disecar el conocimiento en una nota o en un 'síndrome' como supone la noción de 'déficit atencional'.

$\mathrm{Al}$ realizar evaluaciones, nos figuramos que niños y niñas contestarán con una motivación semejante, ante preguntas y evaluadores neutros. Investigaciones recientes demuestran que jóvenes de subculturas diferentes (por ejemplo, la Navajo-americana), no contestarán las preguntas si suponen un contexto competitivo hacia sus compañeros o compañeras. En ocasiones no se encuentran motivados a mostrar sus conocimientos conceptuales, pues no otorgan relevancia ni al guión ni a las tradiciones sociales de la escuela (cf. Rogoff, 1994, 1997). Un test puede ser una situación confusa para aquellas personas con menor experiencia escolar (Rogoff, 1990).

Esta visión sociocultural del aprendizaje como la transformación de la participación de las personas involucradas suscribe la idea de una comunidad de aprendices; la situación óptima es aquella en que esta comunidad toma decisiones sobre las metas y las actividades, aún cuando los papeles sean asimétricos, pues no se intenta disimular o ignorar el papel de los adultos y adultas como mediadores de la cultura. Se valora la posibilidad y la responsabilidad mutua, tanto de adultos 
como de niños, en tomar iniciativa ante las metas y los procesos de aprendizaje.

La organización de la participación, el compromiso y la creatividad de las personas involucradas se convierte en nuestro foco de análisis. Es relevante referirnos a Bruner, Montessori, Vygotsky y Wallon, quienes suscriben una visión de participación cultural explícita. Estas corrientes del pensamiento pueden tornarse estáticas al omitir el análisis de las actividades culturalmente relevantes, para convertirse en métodos más o menos divertidos de presionar a los pequeñines a adquirir conocimientos académicos preprogramados, obviando la noción de participación cultural significativa.

\section{¿Somos directivos o centrados en-el-niño?: falsos opuestos en la búsqueda de diálogo}

Pues bien, quisiéramos entablar una discusión en torno a los significados e implicaciones de términos cuyo uso prevaleciente en la literatura y el discurso educativo, lejos de orientar el trabajo de la educadora y el educador, lo confunden y lo mistifican. Los conceptos e ideales que ponemos en cuestión suelen ser aglutinadas en dos bandos:

En el polo de la-no-directividad encontramos:

- $\quad$ enseñanza centrada-en-el-niño,

- dirigirnos hacia "las necesidades de los niños",

- autonomía,

- creatividad.

En el polo de la enseñanza programada ubicamos:

- directivo,

- hábitos,

- destrezas,

- aprestamiento,

- $\quad$ estimulación, estimulación temprana.
¿Somos directivos o directivas? ¿Propiciamos la autonomía? Son interrogantes que guardan escasa correspondencia con la naturaleza integrada y social del ser humano en la cultura.

El ideal de una enseñanza centradaen-el-niño cierra los ojos ante nuestros cimientos más profundos, cuando de bebés fuimos concebidos y construidos desde los apuros, las palabras golpeadas, las súplicas, las inseguridades y frustraciones, el estilo de construcción de las viviendas, los barrios, los megamercados, el comportamiento de la flota automovilística, el valor de la tierra, la dolarización de las playas y de los refugios remotos, las formas culturales de enamorarse, de cantar, de hacer el amor o el sexo, de parir, de lactar.

Personalmente, cuando escucho hablar de fomentar la autonomía, en seco, como la meta más importante, pienso: ¿y la solidaridad, la comunicación, la unión, la interdependencia? Cuando escucho hablar de no-directividad, recuerdo aquella multiplicidad de investigaciones de los años sesentas que demostraban fehacientemente que los terapeutas y las terapeutas, supuestamente no-directivos, lograban guiar las conversaciones con sutiles claves corporales indicadoras de mayor interés, sutil aprobación o desaprobación.

La no-directividad, pues, no existe. Reaccionamos subjetivamente a pesar de nuestros esfuerzos por ser objetivos $u$ objetivas, y desde esas sutiles reacciones influimos a los educandos (Capra: 1982).

Calificamos con desdeño la enseñanza directiva. Pero pasamos por alto que nuestras aulas y edificios escolares dan una serie de mensajes, espacios generalmente diseñados para 'la no-distracción', la enseñanza en grupos numerosos, la apatía que permitiría centrar la atención en la transmisión de conocimientos desde el docente o la docente. Diseñados porque $a s i$ se-supone-que-sean, en aras de la pasividad y las líneas de 'participación' verbal estipuladas, resultan plasmados en estructuras 
de cemento (húmedo), con ventanas altas para evitar accidentes y distracciones. (Desafortunadamente, también evitan la entrada de la luz, el aire, el verde de la naturaleza).

Estos conceptos unilaterales distraen nuestra atención de la responsabilidad de analizar con ojo crítico los elementos que aportamos al centro educativo. Nos hace perder capacidad de análisis sobre nuestras actuaciones. Se nos olvida colocar nuestra mirada:

- $\quad$ en los significados aportados por la disposición del ambiente y los materiales;

- $\quad$ los contenidos curriculares;

- los libros de texto aburridos, en parcelas y conocimientos dosificados;

- las palabras y los conceptos sobreutilizados;

- $\quad$ los tonos y gestos uniformes que las marcan.

\section{La camisa de fuerza de la educación vista como la aplicación del currículo: los educadores y educadoras como técnicos}

Lejos de analizar los elementos culturales, comparamos a los jóvenes y las jóvenes e intentamos detectar problemas ("niñoproblema, con déficit atencional") como si los programas y el currículo fuesen elementos neutros. Muy por el contrario, las palabras de Pérez-Gómez nos recuerdan:

"es evidente que los estudiantes aprenden mucho más y mucho menos, en todo caso distinto, de lo que se les enseña intencionalmente en el currículum explícito. Tanto los intercambios académicos como los intercambios personales o las relaciones institucionales se encuentran mediatizadas por la compleja red de culturas que se intercambian en este espacio artificial y que constituyen una rica y espesa tela de araña de significados y expectativas por la que transita cada sujeto en formación, precisamente en el periodo más activo en la construcción de sus significados y de su identidad. Esta perspectiva cultural pretende estimular nuestra sensibilidad ante la decisiva influencia socializadora y educativa de los múltiples elementos subterráneos, tácitos e imperceptibles que constituyen la vida cotidiana de la escuela. Los ritos, las costumbres, las formas de organizar el espacio y el tiempo, los consensos no discutidos, las ideas omnipresentes, las expectativas no cuestionadas, los intereses inconfesados, los códigos aprendidos y reproducidos de forma mecánica, los guiones sobreentendidos [...] son todos elementos fundamentales de cada una de las culturas y de la red específica que se articula en el cruce de las mismas (sic), cuyo influjo real en el intercambio y construcción de significados es más poderoso cuanto más imperceptible (Pérez-Gómez, 1998:18)”.

En la práctica, el elusivo ideal de una enseñanza 'centrada-en-el-niño' contradice nuestra necesidad imperiosa de enseñar destrezas y hábitos dentro de un currículo preestablecido que-hay-que-cumplir. Evidentemente, no se tolera el caos que representaría la supuesta no-directividad.

Ante ese dilema irreconciliable, nos damos por vencidos y vencidas de la siguiente manera: por lo visible y lo contable, decidimos seguir adelante con la enseñanza de destrezas, hábitos y conocimientos. Seguimos las parcelas convencionales del programa curricular que hay-que-cumplir y para el cual fuimos minuciosamente entrenados y entrenadas a redactar sus objetivos fragmentarios.

Pero lo hacemos culposamente, pues hay-que-fomentar-la-autonomía. Intentamos dirigir y coordinar a los niños y niñas en forma velada, para que no se note. Con la voz cargada de almíbar y diminutivos, tratamos de endulzar nuestra expectativa para que se realicen las cosas como previsto. Que en el período de círculo o en las clases, los niños y niñas participen, estén atentos, bien sentados, sin conversar. Que aprovechen los ejercicios minuciosamente preparados, que pinten o escriban con cuidado. Que hagan ejercicios de desarrollo motor grueso o motor fino en los períodos previstos. Que sean creativos cuando se espera que lo sean, en el espacio y el tiempo asignados, con los medios que ponemos 
a su disposición. Todo esto, por supuesto, ¡sin que se noten mucho las directrices!

Tarea imposible. Al aceptar estos ideales dicotómicos, en blanco y negro, nos metemos en un callejón sin salida. ¿Cómo guiar y coordinar en forma indirecta, sin que se note mucho, disimulando nuestra culpa? El resultado: no expresar las cosas directamente para no parecer controladores, autoritarios, "directivos".

Este intento de solución no es eficaz: por igual se aburren los chicos y las chicas, nos desgastamos como docentes. Entre nuestra frustración y este dilema, a pesar de nuestra voz entrenada, se nos escapa la confusión, la desaprobación, la pasivo-agresividad, el sentimiento de impotencia.

La bifurcación entre ideales de corte no-directivo y aquellos centrados en la transmisión del conocimiento enturbia nuestra reflexión. Estas dos vertientes, contradictorias entre sí, coinciden, paradójicamente, en una serie de aspectos (Giroux, 1990):

- Una noción truncada de las funciones de la educación, al concebirse como un mundo desligado de la vida, obviando hacia dónde va dirigida.

- Una implícita defensa de una perspectiva que niega el peso de los modelos teóricos; éstos, por tanto, devienen pre-conscientes. Se defienden a ultranza las actividades, la programación, el logro de destrezas y objetivos, sin tener claro que representan una cosmovisión, toda una forma de ver el mundo, de actuar y sentir nuestro lugar en él.

- Ausencia de análisis crítico de las funciones latentes de la escolarización, que actúan como mecanismos ideológicos, orientándonos hacia una adaptación pasiva, hacia lo socialmente establecido, a ver

\section{el mundo como un hecho natural e incambiable.}

- Una visión de los aprendices y las aprendices como depositarios del conocimiento, haciendo caso omiso al contexto en el cual se entretejen las actividades de "enseñanza" o "aprendizaje” (Rogoff, 1994, 1997).

El énfasis en las destrezas, en los objetivos concretos, conducentes a la ilusa esperanza de controlar la enseñanza y el aprendizaje, desconoce los fines amplios, conscientemente asumidos, de importante envergadura. Por ejemplo, al esgrimir el concepto de estimulación, no sólo nos basamos en un mito sino que dejamos de lado lo importante para resaltar hechos aislados ${ }^{5}$.

Por otro lado, quienes abogan por la autonomía han reducido sus miras a la inmediatez del aula, ignorando las determinaciones políticas, culturales y de la vida cotidiana en la conformación de la psique, tanto de niños y niñas como de educadores y educadoras. Contribuyen a perpetuar la sociedad tal y como la encontramos.

Podríamos pensar que la diferencia es trivial. No lo es. Porque cuando creemos actuar 'centrados-en-el-niño', se nos olvida poner atención a la otra gran parte de la ecuación: el inevitable aporte de nuestros valores y hábitos culturales en la formación de los pequeños y pequeñas, nuestra incidencia en el ambiente. Al dejar de examinarlo, se nos pasa inadvertido, vale decir, no concientizado.

\section{¿Es el niño o la niña quien falla en el sistema escolar o el sistema escolar el que les falla?}

"Encontraréis separadas, en la escuela, la difusión de los conocimientos y la formación del carácter. Esa situación es en cada individuo una tragedia y así en la vida del país y en el corazón de la humanidad. Los 
conocimientos de un lado, de otra las ideas, de otro las acciones. Ni un hilo los ata" Omar Dengo (1961: 355).

Son palpables las implicaciones de este paradigma para la evaluación. La concepción del aprendizaje como transformación de la participación de las personas involucradas no se pregunta sobre conocimientos adquiridos sino sobre los cambios de comprensión, motivación y colaboración en las actividades en las cuales participamos tanto educadores como educandos.

Más que intentar derivar una nota "objetiva", las interrogantes se centrarían en cómo cambia el involucramiento de las personas en las actividades. Si el propósito es ayudar a los niños y niñas en torno a su desarrollo cognoscitivo, es más informativo comprender cómo se desenvuelven en la dinámica de las interacciones sociales que administrar un test (Brown y French, 1979).

En lugar de orientar nuestros esfuerzos hacia la detección de los chicos rezagados o problemáticos para etiquetarlos, para derivarlos hacia el sistema médico, intentaríamos preguntarnos sobre la relevancia de las actividades que impulsamos en nuestros centros educativos. Nuestro foco de atención se dirige, entonces, a evaluar el tipo de actividades que como docentes propiciamos, lo mismo que sus significados, más que a rebajar nuestras metas hacia objetivos contables. Evaluar el sistema educativo sería nuestro propósito, al poner en el tamiz de duda nuestros fines curriculares, sus significados, y los ambientes-situaciones que promovemos.

Asimismo nos preguntaríamos cómo transformar ya sea su motivación o las finalidades del sistema. Pero, ¿cómo convencer a pequeñuelas y pequeñuelos desmotivados, compitiendo con las explosivas imágenes y la pasividad que encuentran en la titilante programación televisiva?

\section{¿De quién es el déficit atencional?}

"No es al fin y al cabo tan difícil darse cuenta de que nuestro horizonte es limitado: la dificultad auténtica consiste en tener la valentía de entrever otro, más allá del que conocemos, en abrir una rendija para que el sentido de lo sacro y del misterio vuelva a revitalizar nuestro días." Susana Tamaro (1998: 123).

Traicionamos a nuestros niños y niñas por una inversión de prioridades. ¿Su formación? En manos de una familia desintegrada, atribulada, apresurada, cuyos valores y poderes se encuentran diluidos y fragmentados. En manos de un grupo de pares aislado y homogéneo, de una escuela que no se ocupa de la vida. En manos de una pantalla de televisión dirigida por valores consumistas, que fragmenta la atención y los impulsos de acción. ¿De quién, entonces, es el déficit atencional? Tal vez lo más grave sea que no nos tomemos ni suficientemente en serio ni suficientemente en broma como proyecto humano.

El lenguaje técnico de nuestro entrenamiento esconde los actos cotidianos, que quedan fuera del ámbito de reflexión. Se nos olvida hablar de abrazos, de chorrear café, de aprender a correr con ganas, de pintar o cortar o armar hasta saciarnos. Omitimos examinar en las paredes del centro educativo los signos visibles de la pobreza y la historia del descuido, los espacios encementados de concepciones estatales de pobreza.... Los planes de trabajo hacen caso omiso a los jalones de brazo; a la voz cargada de cansancio, impaciencia, frustración, a los tonos dulces disimuladores del control. No discuten cómo se siente el ser tratadas o tratados con desgano, con sorna, con lenguaje infantilizante, con ejemplos e ilustraciones ajenos a la realidad. Esto es lo que no mencionamos, lo que ha sido desalojado de nuestros propósitos y planes semanales.

No nos engañemos: nuestro proceso dirigido a los diagnósticos y etiquetas es 
nocivo, desde la perspectiva de una educación tendiente a la paz, la creatividad y la participación ciudadana comprometida. Disminuimos la autoestima y desempoderamos las capacidades de los pequeños y pequeñas designados como los más problemáticos (a decir bien, aquellos y aquellas que no nos dejan avanzar con nuestra programación). También lesionamos el sentido de solidaridad de aquellas y aquellos etiquetados como sobresalientes, al transmitirles una cosmovisión competitiva (cf. Miller, 1994).

Es evidente que este cuestionamiento no lo puede realizar cada docente-a-cargo-de-grupos-supernumerarios, de forma individual. El ritual de rutinas cuyo objetivo más evidente es obtener el pase para el próximo nivel en el sistema, logra la importante función de saturarnos, de ocupar nuestro tiempo y nuestro poder de reflexión, preparándonos para la aceptación sin cuestionamientos de las orientaciones oficiales y para convertirnos en piezas adaptadas al engranaje sociopolítico imperante.

$\mathrm{Al}$ detenernos, en conjunto, a reflexionar sobre estos constreñimientos sociohistóricos, diversos autores han realizado investigaciones pormenorizadas sobre las tendencias de fines del siglo XIX, principios del XX, para uniformar los movimientos educativos, tendencia sociopolítica cuya meta es un currículo abstracto, lavado de asideros para asumir nuestro poder regional, nuestro poder contestatario (Bourdieu y Passeron, 1977; Carnoy, 1974; cf. Chavarría, 1982, 1993; Chavarría et al., $\left.2000^{\mathrm{a}}, 2000^{\mathrm{b}}\right)$.

Concebir una enseñanza ya sea 'centrada-en-el-niño' o programada no es inocuo, sino nocivo. Distrae nuestra atención de la perentoria necesidad de examinar y proporcionar las relaciones humanas vinculares y el bagaje cultural que inconscientemente transmitimos a los pequeñines. Este es el lugar acrítico donde la teoría mistifica y empobrece en vez de potenciar e instar a la reflexión.
Lenguaje de frustración para educadores-educadoras y niños-niñas, quienes intentamos subsistir en una rutina que nos fragmenta, nos aliena, nos desempodera para vivir y cuidarnos como comunidad y como especie.

\section{Notas}

1. Este artículo fue escrito como parte del proyecto de investigación "Preescolar con principios de paz y desarrollo sostenible", auspiciado por el Instituto de Investigaciones Psicológicas, el Centro Infantil Laboratorio y la Embajada Real de los Países Bajos. Agradezco los comentarios de las colegas Gilda Barboza Lépiz, Teresita Cordero Cordero, Cynthia Orozco Castro y Marco A. Quirós Méndez.

2. El concepto de influencia recíproca se considera débil en una concepción dialéctica o transaccional, donde la propia definición de los conceptos depende de las estructuras socioeconómicas que afectan nuestras definiciones y enfoques científicos.

3. Para una mayor referencia a los conceptos de investigación etnográfica y de los seres humanos como agentes de transformación, consúltese Chavarría, Orozco, Chacón et al., 2000ª $2000^{\text {b. }}$

4. El desarrollo y el aprendizaje son actualmente considerados indistinguibles entre sí, al analizar que los procesos de aprendizaje son más similares al desarrollo de lo que se pretendía (Bickhard, 1992).

5. Para una crítica histórica y epistemológica puede consultarse Chavarría, 1982.

\section{Referencias bibliográficas}

Apple. M.W. Educación y poder. Barcelona: Paidós. 1988.

Bickhard, M. "Scaffolding and self-scaffolding: central aspects of development". En: Winegar, L.T. y Valsiner, J. (eds.), Children's develoment within social context, volume 2: Research and Methodology. New Jersey, 
N. Y.: Lawrence Erlbaum Associates. 1992.

Bourdieu, P. y Passerson, J.C. La reproducción. Paris. 1977.

Brown, A. L. \& French, L. A. "The zone of potential development: implications for intelligence testing in the year 2000". Intelligence, 3, 255-273. 1979.

Bruner, J. Towards a theory of instruction. New York: W.W. Norton. 1966.

Capra, F. El punto crucial. Barcelona: Editorial Integrar. 1982.

Carnoy, M. Educación como imperialismo cultural. Mexico D. F.: Siglo XXI. 1976.

Chavarría, M.C. "La estimulación temprana: Apuntes sobre fundamentos teóricos, bases empíricas y raíces sociohistóricas." Revista de Ciencias Sociales (Costa Rica) 23; 41-56. 1982.

Chavarría, M.C. Tendencias sociopolíticas de la educación preescolar: El dilema de la madre trabajadora. San José: Editorial de la Universidad de Costa Rica. 1993.

Chavarría, M.C.; Orozco, C.; Chacón, Y. y Ovares, M. "Aciertos y vicisitudes en la búsqueda de valores hacia la paz y el desarrollo sostenible: la decodificación de lo cotidiano como herramienta teórico-práctica". $R e$ vista Costarricense de Psicología, 31. $2000^{\mathrm{a}}$.

Chavarría, M, C.; Orozco, C.; Chacón, Y.; Ovares, M., y Obando, M. del M. "La formación del preescolar como cosmovisión: en busca de valores hacia la paz y el desarrollo sotenible". Educación: Revista de la Universidad de Costa Rica, 24 (No. 2), 115-132. $2000^{\mathrm{b}}$.

Dengo, O. Escritos y discursos. Costa Rica: Ministerio de Educación Pública. 1961.

Freire, P. Pedagogía del oprimido. México, D.F.: Siglo XXI. 1986.

Fromm, E. Man for himself. Grenwich, Conn: Fawcett Publications. 1965.

Gergen, K. Personality and social behavoir. N.Y.: Addison-Wesley. 1970.

Giroux, H. Los profesores como intelectuales. México D.F.: Editorial Paidós. 1990.

Kamii, C. \& Devries, R. "Piaget for early education". En: The pre-school in action: Exploring early childhood programs. M. C. Day \& R. A. Parker (eds). Boston: Allyn \& Bacon. 1972.

Kliebard, C. En: Current Thought on Curriculum. 1985 ASCD Yearbook. 1987.

Lave, J., y Wenger, E. Situated learning: Legitimate peripheral participation. Cambridge, England: Cambridge University Press. 1991.

Léfèbre, H. Critique de la vie quotidienne. París: L'Arche E'd.(La vida cotidiana en el mundo moderno: Madrid: Alianza Editorial). 1961, 1972.

Lündgren, V.P. "Curriculum from a global perspective". En: Current Thought on Curriculum: 1985 ASCD, yearbook. 1987.

Miller, A. El drama del niño dotado y la búsqueda del verdadero yo. Barcelona: Tusquets Editores S. A. 1994. 
Pérez Gómez, A. La cultura escolar en la sociedad neoliberal. Madrid: Editorial Morata. 1998.

Rogers, V. R. "Cualitative and aesthetic views on curriculum and curriculum-making”. En: Current Thought on Curriculum: 1985 ASCD Yearbook. 1987.

Rogoff, B. Apprenticeship in thinking: cognitive development in social context. New York: Oxford University Press. 1990.

Rogoff, B. "Developing understanding of the idea of communities of learners". En: Mind, Culture, and Activity, Vol. 1, No. 4. 1994.

Rogoff, B. "Evaluating development in the process of participation: Theory, methods, and practice building on each other". En: E. Amsel \& A Renninger (eds), Change and development. Hillsdale, N.J.:Erlbaum. 1997.

Rojas, M. Educación científica y matemática para el niño preescolar. Perspectiva constructivista. San José, Costa Rica: Editorial EUNED. 1998.

Roszak, T. (ed). Ecopsychology. San Francisco: Sierra Club Books. 1995.
Tamaro, S. Querida Mathilda: No veo el momento en que el hombre eche a andar. España: Editorial Seix Barral. 1998.

Vygotsky, L. Historia del desarrollo de las funciones psíquicas superiores. La Habana: Editorial Científico Técnica. 1987.

Vygotsky, L Thought and language. Cambridge, Mass.: MIT Press. 1962.

Weikart D.P. Organizational schemes for pre-school curriculum models, Ypsilanti, Michigan: High Scope Educational Research Foundation. 1971.

Werner, C. y Altman, I. A dialectical transactional framework of social relations: children in secondary territories. En: Children, cities and psychological theories. Görlitz, et al. (eds). Berlín: Walter de Gruyter. 1998.

Wertsch, J.V. Vygotsky y la formación social de la mente. Barcelona: Paidós. 1988.

Wolfson, B.J. Psychological theory and curricular thinking. En: Current Thought on Curriculum: 1985 ASCD Yearbook. 1987.

María Celina Chavarría: Investigadora en el Instituto de Investigaciones Psicológicas de la Universidad de Costa Rica (UCR). 
